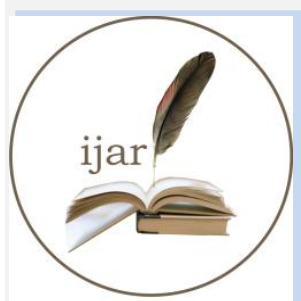

ISSN NO. 2320-5407
Journal Homepage: - www.journalijar.com INTERNATIONAL JOURNAL OF ADVANCED RESEARCH (IJAR)

Article DOI: $10.21474 /$ IJAR01/1355

DOI URL: http://dx.doi.org/10.21474/IJAR01/1355
INTERNATIONAL JOURNAL OF ADVANCED RESEARCH (JJAR)

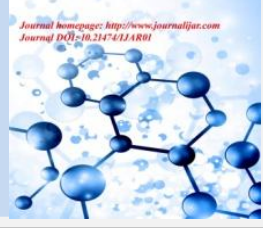

RESEARCH ARTICLE

\title{
DRAMATISTAS LITERARY JOURNALIST: THE RHETORICAL STRATEGIES OF ANNA DEAVERE SMITH'S ONE-WOMAN PLAYS.
}

Ann Meejung Kim.

Yonsei University, Seoul, Korea, 50 Yonsei-ro, Seodaemun-gu, Seoul, Korea.

\section{Manuscript Info}

Manuscript History

Received: 12 June 2016

Final Accepted: 19 July 2016

Published: August 2016

Key words:-

documentary theatre, Anna Deavere

Smith, literary nonfiction, literary

journalism, dramaturgy, nonfiction theatre.

\section{Abstract}

This paper examines Anna Deavere Smith's documentary drama in relation to the literary journalism tradition, paying attention to the author's primary impulse in employing the techniques and mode of writing. Then, focusing on the genre of her choice, theatre, it examines how her performance of the text subverts and variegates the tradition in nonfiction writing, by simultaneously reminding the audience of the text's non-fictionality and the ultimate fictionality of any creative work. It is a testimony against the ultimate unobtainability of absolute truth, which is also the motivation of documentary theatre - to question reality and serve as catalyst for social action.

Copy Right, IJAR, 2016,. All rights reserved.

\section{Introduction:-}

According to the theatre critic Attilio Favorini, documentary theatrehas a history as long as the history of theatre itself (Favorini 1995). It is recognized by the usage of pre-existing documentary material, such as newspapers, government reports, interviews, etc., as the source material for the script, often without altering the words. Aside from source material, what differentiates it from other genres of drama is often that it frequently deals with political and social content, ideally serving as the catalyst for change.

In addition to being a prime example of documentary drama, Anna Deavere Smith's plays are additionally acclaimed for Smith's performative prowess as an actress. A scriptwriter as well as performer, she is known for her unique style in both her methodology in writing and performance. Her style of researching and writing is akin to the techniques consolidated by some literary journalists, which is often involves relationship building with interviewees. This paper will firstly look athow and why Smith incorporates literary journalisticelements in her documentary drama, most importantly in the On the Road series.Secondly, focusing on her genre of choice, theatre, which is always written with performance in mind, I will look at how Smith's particular performances travel and amplify themselves to the audienceassimultaneously factual and non-factual. Ultimately, by illustrating how Smith blurs the boundaries of fiction or nonfiction, I will examine how she successfully creates a new space and possibility for literary "nonfiction" in the broadest sense.

Anna Deavere Smith's Dramaturgy and Performance:-

Twilight: Los Angeles 1992, Fires in the Mirror and other works by Anna Deavere Smith in On the Road: A Search for American Character series, employ a unique method in composition and performance. Theyare parts of Smith's larger, ongoing experimental project that she started in 1980s. She conceived of a series of plays that would consists

Corresponding Author:- Ann Meejung Kim

Address:- Yonsei University, Seoul, Korea, 50 Yonsei-ro, Seodaemun-gu, Seoul, Korea. 
solely of authentic American voices, voices that typically go unheard, that she would perform solely by herself. Carrying a tape recorder, Smith conducted hundreds of interviews with people related to the subject and wrote the plays based on the actual words spoken. Then, she performs the entire play by herself, impersonating the interviewees. In effect, she changes into many characters, casting herself multiple times in these "one-woman" plays.

What this procedure and strategy means is that the written work and performance are essentially different works in terms of audience experience. In the written form, the script reads like a factual transcription of those interviews, albeit in a more polished, poetic format. It is neither expected nor implied that they originate from the same person. For this reason, more credence is arguably given to the factual nature of the writing. In performance, however, some of that credibility is diminished, as it is plainly visible to the audience that Smith is performing as all the characters. Her writing, it can also be argued, makes good use of the techniques consolidated by some nonfiction writers, documenting factual records with a literary flair.Watching Smith perform the entire play by herself, however, enables the viewer to experience somethingentirely different from the text, in the sense that the "factual" text is now"simulated reality" based on the complicit deception between the actress and the audience. Such performance allows Smith to go beyond a simple documenting eye, a reporter, and move seamlessly between her roles as dramatist, actor, and social activist.

It was not until she came to have a specific focus, however - a political focus - racial conflicts emerging from economic and social class difference - that she captured the attention of a larger audience. In Fires in the Mirror (1991), she chronicles the racial conflict between blacks and Jews in Brooklyn through multiple voices from both groups. For Twilight: Los Angeles 1992, Smith interviewed people directly or indirectly involved in the L.A. Riots of 1992, concentrating on the racial tension in the South Central area. Both plays were well-received critically and commercially, but it appears that reviewers were at a loss to define exactly what it was. One journalist writing for Newsweek conveniently overlooked defining it, calling Twilight a "collage-drama-documentary-epic poem-living movie" (Knoll). Another reviewer tried a little harder, saying that the play "combined the traditions of theatre and journalism in a powerful new way ... virtually inventing a new art form" (Blanchard 31). He also fails to explain, however, what exactly is "new" about it and why, compelling us to question whether anything indeed is new about the play aside from the incredible talent of the writer as actress. In another statement, he reluctantly offers his definition of it, calling it "theatrical documentary."

Smith, on her account, declared the play "a form of documentary theater" (Twilight 4). In the general production note preceding the text of Twilight, she states that it is essential that prior to the performance, the actors should be "given a lot of research material" or even "participate in the research" in preparation. The play depends on the "informed actor" (4), as it is about a "real event, using the words of real people." Even more, the audience should be made aware of the play's basis on actual events. In other words, Smith requires that both parties, the actress and the audience, should "do their work" before coming to theater. In other words, they should be fully aware of the nonfictional aspect of the play, and have ample background information about the subject matter before they even come into contact with the play in either written or performed form. In modern popular culture, such declaration can perhaps be compared to the "Based on a True Story" stickers attached at the beginning of movies, which "sets the stage," and thus completely colors the viewing experience.

Smith is not aiming for any cheaply bought reality, however, as her research is much more authentic than such superficial claims to truth. She painstakingly emphasizes the factuality of the play, stating that all words were taken "verbatim" (4). Lee Yonghee calls Smith an "anthropologist in theatre," pointing to the difficult work she has to undertake to persuade people to "talk to her" (Lee 84). Smith's research process is indeed arduous and extensive. She compares her tape recorder as her "camera," (Talk 80), by which she means it is her official "record" of truth. She interviewed those who are already in the public eye, then asked them to point to a person whom they think have something to say. After amassing a large collection of voices, she selected the interviewees, and arranged them in rhythmic lines reminiscent of poetry. This process can be compared to what journalists do during the informationgathering process and subsequent write-ups. However, Smith confesses she does not see herself as a "journalist":

I don't have a press pass. I can't work as quickly or with as much savvy as journalists can. Journalists have the equipement, the system, and the expertise to be on the pulse of the moment. I'm always a few seconds behind. (Blanchard 35)

It is notable how she understands the work of a journalist as fast-paced, efficient and, most surprisingly, expert. Yet, 
while her understanding of journalists and what they do may closely resemble that of ordinary people, it may be too simplistic. In fact, a particular breed of journalism, which utilizes some literary techniques of writing ordinarily associated with fiction, may actually be close to what Smith does. Journalism scholar Sims categorizes journalism which took hold of American journalism since the 1890s into two broad breeds: "scientific" journalism, whichfocused on reporting secondhand information and statistics, and another kind of journalism, which was characterized by its impulse to be directly involved with the subjects, often referred to as "participant observation" (xviii), similar to those practiced by anthropologists working in the field.Many examples of longer journalism works exists that are slow, inefficient, unpretentious, and creative in its making, such as those by Ted Conover, who lives with his subjects for longer periods of time, such as prison guards and hobos,to write his journalistic pieces. But the distinctive feature that ultimately aligns her with literary journalists or literary non-fiction is her uniquely humanistic approach. In the next section, I will speculate why this approach appeals and befits Smith's work.

\section{The Dual Attractions of Literary Journalistic Method:-}

Whereas traditional journalists, or even documentary makers, try to avoid getting too close, ensuring a certain distance that they believe will give them objectivity, literary journalists are really looking to get to know the subject, to establish a certain connectedness which, in the end, yields more meaning than simple facts (Sims 301). What this also signifies is that such slower pace requires not only more effort and perseverance but also time and money, which are not always available to writers. This investment, while difficult to obtain, has one decisive advantage: if one explores so deeply, it is possible to uncover previously unheard stories. This is precisely what was important to Smith. In choosing to listen to "unheard voices" (Blanchard 35) engaging deeply with the subjects, she implicatesherself in their story in order to bring the story out. Rather than starting with a story then finding evidence to back up, Smith and other literary journalists work the other way around: they start from the bottom up, waiting for the story to emerge naturally by talking to and observing people. This impulse to get closer to the subjects, and to reveal that closeness to the audience in order to gain credibility, is an entirely different instinct from the impulse that motivates traditional, pace-driven scientific journalism.

For instance, Smith has said that Mrs. Young-Soon Han in Twilight, the Korean American merchant whose store had been destroyed during the L.A. riots, has "taught [her] the most that I have learned about race" (YouTube). Part of that lesson comes from the fact that Mrs. Han's voice, like many others in the play, is a "buried voice," something the mainstream media has not told. Yet, as noted by scholars in journalism, there is another important reason to take longer time to carry out literary journalism, which is the literary, or aesthetic, character of the prose. This aspect is also illustrated in Mrs. Han's voice, as from the sheer power of her words emerge a picture that is more real that any description.

Is it because we are Korean?

Is it because we have no politicians?

Is it because we don't

speak good English?

Why?

Why do we have to be left out?

(She is hitting her hand on the coffee table.)

We are not qualified to have medical treatment!

We are not qualified to get uh

Food stamps!

(She hits the table once.)

No GR!

(Hits the table once.)

No welfare!

(Hits the table once.)

Anything!

It is easy to notice the rhythmic syntactic pattern naturally emerging in the midst of this woman's passionate words. Such "organic poetry," as Smith puts it, is "often more brilliant and more vital than the conventional drama we typically go to the theater to hear" (Blanchard 36). In patiently seeking a "revealing remark" and "mentally editing" (Favorini 303), the story that emerges by itself is more powerful than any narrative with a carefully set agenda. Thus, the attractions of literary journalistic method to Smith are twofold: it requires a slower pace of work, enabling 
her to uncover more grounded stories, while simultaneously allowing her to work in the literary realm, which is also important to her.

\section{The Question of Truth:-}

That kind of perspective, however, can too easily discredit the creative non-fictional impulse as being motivated by selfish reasons. Likewise, if we cannot entirely buy a movie's "Based on a True Story" declaration, suspecting its authenticity even as we are being engrossed in the story, what does truth mean in literary nonfiction, and in Smith's work? Attilio Favorini points out that all representations of history are the making of history (Favorini 105). He argues that it is for this reason that documentarians and historians are caught in a paradox: documentarians cannot free themselves from their work becoming historicized, and historians cannot but rely on narrative to transcribe history. How can an official truth be established? Smith addresses this problem by questioning the official truth itself (YouTube). Part of her solution may lie in her balanced selection of interviews. For example, right after a person from one race speaks, a person from another race follows. In this way, the audience is constantly thrown one way then the other, necessarily undergoing a rapid mental change of perspective. In her racially themed plays, the different perspectives do not have to work along a strict racial divide, either. For example, Twilight features an African American attorney defending Soon Ja Du, the Korean grocer who killed an African American youth Latasha Harlins, followed immediately by an African American woman who is infuriated by his choice to defend Du. The characters themselves do not always speak from their standardized perspectives, either, as when Mrs. Young-Soon Han displays some sympathy towards African Americans:

They have fought

for their rights

over two centuries

and I have a lot of sympathy and understanding for them.

Because of their effort, and sacrificing,

other minorities like And Hispanic

or Asians

maybe we have to suffer more

by mainstream.

Through such monologues as Mrs. Han's, Smith succeeds in presenting the complexity of the whole event without saying it in so many words. In the careful selection and ordering of the monologues, she creates a certain confusion, but the collective representation "tends to preserve the contradiction of viewpoint inherent in every historical event." (Favorini). In other words, her lack of discernible focus is her weapon against criticisms of subjectivity. Also, rather than focusing solely the most publicized event of the 1992 riots, namely the beatings of Rodney King, she goes back to the roots of the racial tensions, including the shooting of Harlins and beating of Reginald Denny, furnishing the play with more historical groundwork.

\section{Smith's Plays as Performance:-}

Yet, aside from their non-fictional quality, Smith's work is differentiated from those of other literary journalists in one aspect: it is intended to be performed, to travel through auditory and visual experience to the audience. What this means is that the decisive moment of her workmay arrive in the performance, as much as it does - or even more so - in text. Smith herself has described the process of research and performance as "leaving the safe house of identity" (Smith 24). She figures that identity is shaped as much by the particularities of language, such as dialects, slangs, gestures and expressions, as it is by the culture they live in, and that language is directly connected to identity: in a way, it makes identity, and provides a "photograph" of America.

If language is such anintegral part of her work, indeed something that makes up the core of truth, it is notable thatsuch a "photograph" ironically does not exist until Smith hits the stage and performs it, albeit in simulation. In text, it technically does not yet exist, and so the characters' identity is also yet to emerge; in performance it is completed, or comes as close to completion as possible. Herein lies the difference betweendocumentary drama from a nonfiction text intended for reading only: on the one hand, a drama script is a literary text in itself. However, a dramatic text completes itself on stage. In essence, they are actually two different works. And whereas in text and film (in which form Smith's work has also appeared), the outcome is fixed, in performance it transforms itself each time. For example, Smith revises the script each time she performs, exchanging the words "last year" to "1992" (YouTube). 
In case of Smith's documentary drama, the duality is even more complicated because not only are the words (once real) being re-enacted, but Smith, the writer and the confidante of those characters, is playing them. When theatergoers enter the playhouse, knowing something about the context of the play, and have sat through Smith's performance, they have witnessed but a transformation of one person literally becoming many persons. Whereas in traditional theatre, viewers are simply supposed toaccept the actress as her character for the duration of the play, in Smith's plays, viewers are actively prevented from doing so. Instead, they must recalibrate every time she changes into another character. In doing so,Smith constantly reminds the viewer that what they are seeing is not real, indeed cannot be real. This is directly against the simulated reality of fictional texts and drama, where one is supposed to believe in the believability of the fictional text. Conversely, here, it is the denial of the non-fictional texts that are seemingly real, which reminds the reader that the complete truth is of course unobtainable. In this sense, it differentiates itself from literary journalism, which is supposed to be believed.

Seeing character after character manifested in the same body, the audience cannot help but be constantly reminded of the inevitable fictionality in the supposedly nonfictional text, the illusion of obtainable truth. After all, in literary journalism, too, truth and accountability has long been considered an important topic. If Smith's performance is contributing anything in documentary theater, it would be the constant reminder of its self-criticism as a documentary text.

With that knowledge, as well as the understanding that Smith's words were once spoken by real people, the audience is able to have a much richer experience in documentary drama. This is because not only is her work documentary theater based on facts, but also a "theater" of Smith.

At the same time, this characteristic of Smith's work means that such effect relies almost entirely on her performance, and no one else's. As so much of the transformative experience relies on Smith's performance, talent, and pre-existing knowledge of the text arising from her time with the interviewees, the unfortunate result is that it cannot be duplicated. Looking at the instances in which her work was performed by a different cast confirms this. After seeing the City Theatre in Pittsburgh's two-person performance of Fires in the Mirror, the Favorini writes:

Absent the compelling persona of Ms. Smith, the production amplifies the "historical" vibrato of the material ... thus [emphasizing] the information component over the story-telling component ... when her surrogates perform the piece, it can slip into being "about" the acting of "character" in a more superficial sense (Favorini 1996)

In other words, the play's non-fictional, "textual" appeal becomes more emphasized, but the work loses the extra layer of complication and becomes more like an ordinary journalism piece, rather than a literary work. In others' performance, the work's co-existence of fictional and non-fictional elements is lost, because only Smith is the living evidence of the multiple voices she witnessed and now carries. The critic also notes that substitute actors even change that nature of factual information conveyed in the play, noting that even the monitors displaying the scenes from the Crown Heights incident is transformed from a "hot" medium to a "cool" one. In other words, Smith's composition of the text, and her performance of it, is in itself a rhetorical strategy employed by Smith to convey what she ultimately wants to say about the fluidity of identity, perspective and the absence of absolute or official truth. It is also a commentary on the fictional or non-fictional quality of her work.

In Smith's performance, she speaks as many people through their words, but at the same time, Smith is also speaking as herself, an actor, who has compassion and energy to sympathize and want to deliver a message to the audience. Accordingly, Smith sees the actors of the play as a "culture worker" (5), and herself not only a writer but also an activist. It becomes evident to any person witnessing the play that it takes tremendous time and effort to come to such a place, that doing such a work requires dedication, perseverance and love. In creating the text, Smith's work is rooted in the literary nonfiction tradition, taking the role of a conscious observer and exercising her literary sensibilities as a writer. In transforming it onto stage, her characters, while approximating reality, become a kind of "fictional reality." Whereas in conventional plays the audience is expected to believe the actor as the character, Smith encourages the audience to wholly believe the actor as a mimic, which enables them to come to their own conclusions about the racially charged situation at hand. She does not speak to the audience from the actress's realm in the traditional sense, but as an actress's actively stepping into other people's words, putting herself in the limbo between the actor and the real person. She succeeds in persuading the audience of her precarious position, and in doing so, achieves what one-dimensional literary journalism texts could not be do - re-enacting the material back to the audience to shatter their expectations. 


\section{Conclusion:-}

Even in the documentary theatre genre, Anna Deavere Smith occupies a unique space, as her incredible talent enables her to approximate her documented interviews, thereby communicating to the audience that not only are they witnessing a close non-fictional text, but also in a one-of-a-kind performance that constantly reminds them of the fluidity of facts. Smith's documentary impulse is heavily indebted to the participant observer method often employed by literary journalists. The impulse of documentary journalism - to get closer to the subjects to uncover buried voices, and to lend more comprehensive perspective to the issue at hand, preferably in an aesthetically pleasing way - is well suited to Smith's purpose, as she seeks to give voice to unspoken voices, literally and figuratively. It allows her close observation, and even naturally allows her to exercise her literary talent. The medium of her choice, theatre, allows her yet another possibility, which is the subversion of truth and uncertainty. In this way, the audience is never allowed to form a definite stance on the social issue at hand-it is a reminder that nothing can be truly non-fictional, even in the nonfiction realm.

\section{References:-}

1. Blanchard, Bob. (2000). “Drama of L.A.'s Anguished Soul.” Progressive. 57.12 (Dec. 1993). 35-37.

2. Favorini, Attilio. (1994). "Representation and Reality: The case of documentary theatre." Theatre Survey. 35.2 (1994). 31-42.

3. ___. (1996). Rev. of "Fires in the Mirror." Theatre Journal. 48.1 (1996). 105-107.

4. _ (1995). Voicings: Ten Plays from the Documentary Theatre. Hopwell, NJ: Ecco Press.

5. Ki, Hyunjoo. (2010). "Anna Deavere Smith's Twilight: Performative Identity and Racial Borderland.” Journal of Modern British and American Drama. 23.3 (Dec. 2010). 33-52.

6. Kroll, Jack. (1993). "Fire in the City of Angels." Rev. of Twilight: Los Angeles, 1992. Newsweek. 28 June 1993.

7. Lee, Yonghee. (2006). "Anna Deavere Smith as an Anthropologist in Theatre." Journal of Modern British and American Drama.19.2 (Aug. 2006). 83-97.

8. Sims, Norman. (2007). True Stories. Evanston, IL: Northwestern University Press.

9. Smith, Anna Deavere. (2003). Twilight: Los Angeles, 1992. New York: Dramatists Play Service, Inc.

10. _ (2000). Talk to Me: Listening Between the Lines. New York: Random House.

11. TEDtalksDirector. "Anna Deavere Smith: Four American Characters.” YouTube. Web. 17 Dec. 2012. 